\section{Bulletin of Entomological}

Research

\section{cambridge.org/ber}

\section{Research Paper}

Cite this article: Moyano A, Abraham S, Ovruski S, Van Nieuwenhove G, Rull J (2020). Life history, dormancy regulation, reproductive physiology and basic behaviour of the subtropical fruit fly Rhagoletotrypeta pastranai (Diptera:Tephritidae). Bulletin of Entomological Research 1-8. https://doi.org/10.1017/ S0007485320000590

Received: 17 February 2020

Revised: 24 June 2020

Accepted: 27 August 2020

\section{Keywords:}

Carpomyini; dormancy; host-plant phenology; natural history; Trypetinae

Author for correspondence: Andrea Moyano,

Email: andreamyn19@gmail.com

\title{
Life history, dormancy regulation, reproductive physiology and basic behaviour of the subtropical fruit fly Rhagoletotrypeta pastranai (Diptera:Tephritidae)
}

A. Moyano ${ }^{1} \mathbb{D}$, S. Abraham ${ }^{1}$, S. Ovruski ${ }^{1}$, G. Van Nieuwenhove ${ }^{1,2}$ and J. Rull ${ }^{1}$

${ }^{1}$ Laboratorio de Investigaciones Ecoetológicas de Moscas de la Fruta y sus Enemigos Naturales (LIEMEN), Planta Piloto de Procesos Industriales Microbiológicos (PROIMI-Biotecnología), Consejo Nacional de Investigaciones Científicas y Técnicas (CONICET), Tucumán, Argentina and ${ }^{2}$ Instituto de Entomología, Fundación Miguel Lillo, San Miguel de Tucumán, Tucumán, Argentina

\begin{abstract}
With the purpose of broadening knowledge on the evolution of life history strategies and behaviour of fruit flies within the tribe Carpomyini, the natural history and mating behaviour of the poorly known species Rhagoletotrypeta pastranai Aczél, are described for the first time. Larvae of $R$. pastranai were recovered from infested Celtis tala Gillies ex Planch and Celtis iguanaea (Jacq.) Sarg. during a 2-month fruiting period. Adults emerged from the recovered pupae after an average of $144.9 \pm 3.9$ days for females and $143.2 \pm 3.38$ days for males, suggesting that most individuals became dormant. Results of a variable winter length study suggested that environmental factors other than winter length may regulate dormancy/diapause duration in this subtropical species. Under laboratory conditions, $R$. pastranai adults lived an average of $51.13 \pm 3.06$ days in case of females and $48.08 \pm 3.76$ days in case of males, and required 5-15 days to reach sexual maturity. Behavioural observations under confinement revealed scarce sexual activity but sufficed to determine that, as in other members of the tribe Carpomyini, $R$. pastranai exhibits a male resource defence mating system. We discuss our findings emphasizing the importance of documenting the natural history and behaviour of unknown species of family Tephritidae and additionally, we highlight the necessity of future research to understand factors regulating dormancy/diapause and the evolution of life history strategies and sexual behaviour of subtropical species.
\end{abstract}

\section{Introduction}

Insecta comprises the most diverse animal group and occupies almost all environments on Earth. Recent estimates of the number of insect species range between 1.0 and 5.5 million (Mora et al., 2011; Stork, 2018) and about 21-29\% of these species remain to be discovered (Costello et al., 2012). One of the reasons for this information gap could be the disproportionate research efforts focused on economically important or charismatic taxa, whereas other groups, such as many families of beetles, flies and parasitic wasps, have been almost completely ignored (Stork, 2018).

One of the most abundant groups of insects is the megadiverse order Diptera comprises 157 recognized families (Wiegmann et al., 2011) including Tephritidae, whose frugivorous members are known as 'true fruit flies' and include almost 5000 currently recognized species (Norrbom, 2004). Tephritid flies display a wide distribution all over the world, inhabiting tropical, subtropical and temperate areas. One-thousand and sixty tephritid species have been recorded from the American continent, of which 957 have been found in the Neotropical Region from Mexico to Chile and Argentina (Norrbom et al., 1999; Norrbom, 2004; Hernández-Ortiz et al., 2011). Many fruit fly species belong to the subfamily Trypetinae and have relevance since they produce damage and economic losses in fruit production. Within this group, the tribe Carpomyini is composed of 140 species arranged in 12 genera (Smith and Bush, 1999; Norrbom, 2004) that inhabit the Holartic and Neotropical Regions and of which, the genus Rhagoletis is the most recognized. In contrast, most of other genera have been poorly studied and there is scarce information about their natural history, biology, behaviour and phylogenetic relationships (Norrbom, 1994; Smith and Bush, 1999; Rull et al., 2017).

Studies about the natural history of a species form the basis for a good understanding of the ecology and evolution of behavioural patterns. Some aspects, such as adult food, mating or egg laying sites, have been poorly investigated within the Carpomyini, except for several economically important Rhagoletis, Zonosemata and Carpomya species (Prokopy and Papaj, 1999; Boucher et al., 2005; Yee et al., 2014). Regarding sexual behaviour, research to date indicates that the mating system of Carpomyini can be categorized as male resource defence, where 
males are located near or above host fruit, awaiting females that are seeking egg-laying sites. Meanwhile, males defend such sites from intruding males and eventually copulate without any courtship display. Based on studies performed on Rhagoletis pomonella, and a few other species in the genus, both males and females are highly promiscuous, and the last male to copulate fertilizes most of the eggs laid by the female (Opp and Prokopy, 2000). According to available information to date, with the exception of species in the walnut infesting $R$. suavis group, all other Rhagoletis females normally lay only a single egg per fruit (Prokopy and Papaj, 1999; Nufio et al., 2000). Also, the majority of species of Carpomyini are monophagous, stenophagous or oligophagous, and their life cycle includes one full generation per year, exploiting hosts with discrete fruiting periods separated by adverse environmental conditions; consequently, such organisms become dormant during the pupal stage and emerge as adults during the following fruiting season of their host plant, however in some species, part of each generation diapauses for multiple years (Prokopy and Papaj, 1999). After adult emergence from dormant pupae, the majority of adult Carpomyini need to acquire protein for gonadic development (Prokopy and Papaj, 1999). However, there are some exceptions to this rule, such as Haywardina cuculi and Rhagoletis blanchardi which engage in sexual behaviour immediately after adult emergence (Rull et al., 2017; Rull, 2020), suggesting that sexual maturation occurred during metamorphosis using larval stores.

Rhagoletotrypeta Aczél is a small genus of Carpomyini of Nearctic and Neotropical distribution that comprises 12 species placed into two groups (Smith and Bush, 1999). The annulata group includes $R$. annulata Aczél, $R$. argentinensis Aczél, $R$. intermedia Norrbom, $R$. morgantei Norrbom, $R$. rohweri Foote and $R$. uniformis Steyskal while that xanthogastra group includes $R$. cubensis, R. parallela Norrbom, R. pastranai Aczél, R. xanthogastra Aczél, $R$. chapecensis Norrbom and $R$. gelabertae Norrbom (Ovruski et al., 2005; Norrbom et al., 2016). To our knowledge, four species have been found in Argentina associated with host plants belonging to the genus Celtis L. (family Cannabaceae) (Berg and Dahlberg, 2001) such as C. tala Gillies ex Planch. and C. iguanaea (Jacq.) Sarg. (Norrbom, 1994; Ovruski et al., 2005). Both species are native to the Neotropical Region; and can be found in the Yungas and Chaco ecoregions, between 400 and $1200 \mathrm{~m}$ above sea level (Romanczuk and Del Pero de Martinez, 1978). These plants are small trees (8-12 m) whose fruits are almost or entirely spherical drupes with fruiting taking place between late summer and early fall (Dottori and Hunziker, 1994). There are many unknown aspects of the biology and ecology of Rhagoletotrypeta, e.g. duration of life stages, patterns of sexual maturation, mating behaviour and adult longevity; therefore, this plant-insect affiliation constitutes a good opportunity to generate knowledge about a poorly studied genus of tephritid fruit flies. In the present study, we report data on distribution, host-plant associations, infestation and parasitism levels, regulation of dormancy, and demographic and behavioural observations on adults of $R$. pastranai in an effort to contribute to understanding the evolution of life history strategies in the Carpomyini.

\section{Materials and methods}

\section{Study area}

Biological material for this study was obtained from two sites in the Tucumán Province (NW Argentina), one of them with several sampling points along a section of provincial route RP 338 between Villa Nougués $\left(26^{\circ} 51^{\prime} 21.16^{\prime \prime} \mathrm{S}-65^{\circ} 21^{\prime} 52.64^{\prime \prime} \mathrm{W}\right.$, elevation $1112 \mathrm{~m}$ a.s.l.) and San Pablo ( $26^{\circ} 52^{\prime} 4.28^{\prime \prime} \mathrm{S}-65^{\circ} 20^{\prime} 48.77^{\prime \prime} \mathrm{W}$, elevation $664 \mathrm{~m}$ a.s.l.), both localities are situated in Lules department. The second site was located at El Cadillal $\left(26^{\circ} 37^{\prime} 01^{\prime \prime} \mathrm{S}-65^{\circ}\right.$ $11^{\prime} 43^{\prime \prime} \mathrm{W}, 615 \mathrm{~m}$ a.s.l.) in Tafi Viejo department, where sampling took place alongside the road circling a dam. The sampled sites belong to the southernmost end of the Yungas ecoregion (Brown et al., 2006) where mean annual temperature is $18^{\circ} \mathrm{C}$ (Climate-Data.org, 2020) and on account of a strong altitudinal gradient, two different types of vegetation can be distinguished (Brown et al., 2001): pre-montane forest, elevation between 400 and $700 \mathrm{~m}$ with mean annual rainfall between 800 and 1500 $\mathrm{mm}$ and lower montane forest situated between 700 and 1500 $\mathrm{m}$, with mean annual rainfall reaching $2000 \mathrm{~mm}$. Overall, the climate in the study area can be categorized as Cwa according to Köppen and Geiger classification, i.e. subtropical warm-temperate climate with a dry season during the coldest months and rainfall recorded mainly from October to March.

\section{Fruit collection and infestation levels}

Fruit sampling was done by collecting drupes of two Celtis species, C. tala and C. iguanaea (syn. Celtis pubescens (Kunth) Spreng.) during March and April 2018 which corresponds to the fruiting period for both plants. Six Celtis trees were surveyed in Villa Nougués - San Pablo and ten in El Cadillal. Ripe fruits were recovered on and under tree canopies and placed into separate plastic bags for each plant species and locality. Afterwards the same day, the entire fruit collection was taken to the Laboratorio de Investigaciones Ecoetológicas de Moscas de la Fruta y sus Enemigos Naturales (LIEMEN - PROIMI) in San Miguel de Tucumán (Tucumán Province, Argentina). There, collected fruits of each sample were counted and placed in plastic trays inside larger plastic containers $(5000 \mathrm{ml})$ that were capped with a fine mesh-covered lid to allow air passage. Containers were kept under controlled environmental conditions at $25 \pm 1{ }^{\circ} \mathrm{C}, 60 \pm$ $10 \%$ R.H. and a 13/11 h L/D photoperiod and inspected daily to record numbers of larvae and pupae. Pupae/larvae were transferred to $200 \mathrm{ml}$ plastic cups with a mesh-covered lid containing sterilized moist vermiculite and held under controlled environmental conditions (described above) until the emergence of adult flies and/or parasitoids. The time from collection of infested fruit to the emergence of larvae and pupae was recorded to estimate the duration of immature life stages.

To estimate infestation levels for both Celtis species, per cent of infested fruit and the number of larvae per $\mathrm{kg}$ of fruit were calculated. For this purpose, a subset of 35 fruits of $C$. tala and 36 fruits of $C$. iguanaea were weighted and placed individually in small covered $25 \mathrm{ml}$ plastic cups which, in turn, were placed into large plastic containers described above. Individual fruit was also kept under controlled environmental conditions and inspected daily to record the number of larvae and pupae emerged from each fruit.

\section{Emergence of adult flies and parasitoids}

Pupae in $200 \mathrm{ml}$ plastic cups were observed periodically to record adult fly and parasitoid emergence. The time from pupation to adult emergence was used to estimate the duration of development and/or dormancy during the pupal stage. Once emerged, adult flies and parasitoids were kept in plastic cages $(12.5 \times$ 


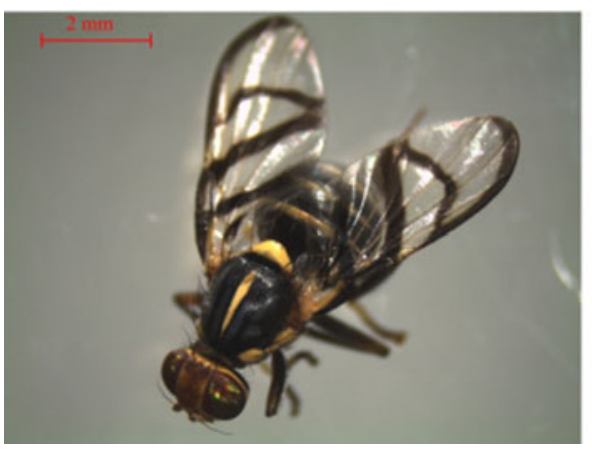

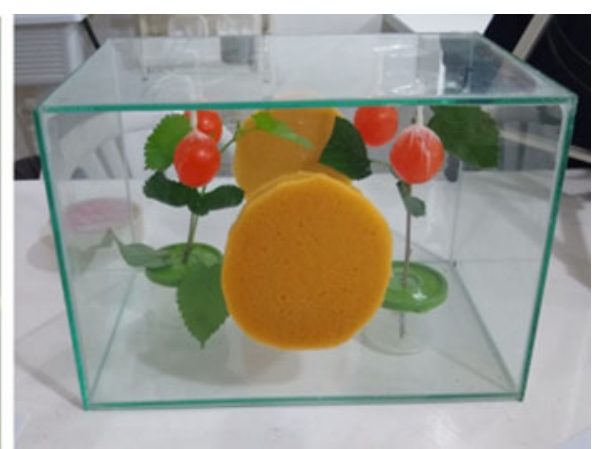

Figure 1. Adult male 13-17 days old Rhagoletotrypeta pastranai used for behavioural observations in an experimental $30 \times 30 \times 60 \mathrm{~cm}$ glass cage with four artificial fruit mimics and five sexually mature $R$. pastranai couples.
$12.5 \times 13.5 \mathrm{~cm}$ ) with free access to water and food for 4 days to allow full wing pigmentation and were preserved in $100 \%$ ethyl alcohol for further identification. Adult fruit fly diet was prepared following Jaldo et al. (2001) and consisted of sugar (57.9\%) (Ledesma S.A., Jujuy, Argentina), hydrolysed yeast (14.5\%) (Yeast Hydrolysed Enzymatic, MP Biomedicals ${ }^{\circledR}$ ), hydrolysed corn (27.3\%) (Gluten Meal, ARCOR ${ }^{\circledR}$ Tucumán, Argentina) and vitamin E (0.3\%) (Parafarm ${ }^{\circledR}$, Buenos Aires, Argentina) (w/w).

\section{Effect of winter length on development and/or dormancy in the pupal stage}

In order to assess the effect of winter length on the duration of development and/or dormancy, pupae recovered from infested fruits of C. tala were placed in $200 \mathrm{ml}$ plastic cups as described above. Subsequently, pupae were submitted to a pre-winter period with control of temperature $\left(25 \pm 1{ }^{\circ} \mathrm{C}\right)$ in the laboratory for 10 days and then subjected to artificial winter periods taking account of the mean temperature in Tucumán during the coldest months is $12.7^{\circ} \mathrm{C}$ with values that rarely reach $0{ }^{\circ} \mathrm{C}$ (Climate-Data.org, 2020). Pupae were separated in 12 cups, two cups per treatment were placed in a conventional refrigerator at $8 \pm 1^{\circ} \mathrm{C}$ for $2,4,6$, 8 and 10 weeks $(\mathrm{w})$ and two cups were left under constant laboratory conditions $\left(25 \pm 1^{\circ} \mathrm{C}\right)$. The sample size for treatment varied according to the number of pupae recovered during inspection of fruit; $2 \mathrm{w}(N=100$ and $N=32), 4 \mathrm{w}(N=24$ and $N=87), 6$ w $(N=22$ and $N=32), 8 \mathrm{w}(N=49$ and $N=29), 10 \mathrm{w}(N=80$ and $N=34)$ and control $(N=164$ and $N=167)$. Vermiculite was moistened with $2 \%(\mathrm{w} / \mathrm{v})$ sodium benzoate solution once a week during the entire experimental period; at the end of artificial winter periods, cups were returned to pre-winter conditions inside the laboratory and emergence of adult flies and parasitoids was recorded for all treatments. One year and two months after fruit collection, uneclosed pupae remaining in cups were separated from vermiculite, counted and inspected to record numbers of live and dead (dry) pupae. The total overwintering mortality per treatment was calculated by adding the number of emerged adult flies and parasitoids and the number of live pupae and subtracting this sum from the total number of larvae recovered after fruit collection.

\section{Age of sexual maturity}

Newly emerged $R$. pastranai adults were sorted by sex and placed in plastic cages $(12.5 \times 12.5 \times 13.5 \mathrm{~cm})$ with free access to water and food. As treatment, two types of diet were provided: (1) adult diet as previously described and (2) sucrose diet. Five 1-, $5-, 10$ - and 15-day-old males and females of both treatments were individually frozen at $-18^{\circ} \mathrm{C}$ for later dissection under a Leica EZ4-D stereoscopic microscope. For males, testes width and length were measured, and in the case of females, size of ovarioles and the number of mature eggs in each ovariole were counted. Additionally, measures of head width were obtained as a control for relative adult size.

\section{Behavioural observations and demography}

On the day of emergence, $R$. pastranai adults were sorted by sex and placed in plastic cages $(12.5 \times 12.5 \times 13.5 \mathrm{~cm})$ with free access to water and food. In total, 40 adults between 13 and 17 days old (sexually mature) were separated for these studies.

For behavioural and mating observations, three glass cages $(30 \times 30 \times 60 \mathrm{~cm})$ were set with two Citrus aurantium twigs and four oviposition devices hung on the ceiling of each cage. Oviposition devices consisted of agar spheres (12 g agar in 250 $\mathrm{ml}$ water) with $30 \mathrm{~g}$ sucrose and 3-4 drops of orange edible dye. Spheres were wrapped with Parafilm ${ }^{\star}$ Chicago, IL, USA, in order to mimic host fruits (fig. 1). On the day before beginning observations, five males and five females were marked on the dorsum of the thorax with a small dot of distinctive acrylic paint to facilitate identification and tracking of individuals. Then, five pairs of marked flies were released in one of the glass cages. Observations consisted of periodical scanning of cages (c.a. every $15 \mathrm{~min}$ ) recording behavioural activities. Scanning encompassed a daily time period from 9 am until 7 pm during 14 days. In addition, five couples were separately placed in $250 \mathrm{ml}$ plastic cups covered with organdi cloth in order to record mating events and copula duration during a period of time from $2 \mathrm{pm}$ until $7 \mathrm{pm}$ for 7 days. Descriptions of sexual behaviour were based on notes taken during observations.

After observations, males and females in the three cages provided with water and food were submitted to a demographic study. Cages were inspected daily and the date and sex of dead adult flies were recorded.

\section{Statistical analysis}

The relationship between fruit weight and number of larvae per fruit was explored using a simple regression. The proportion of adults emerging from pupae exposed to low temperatures for different time periods was compared among treatments using a $\chi^{2}$ test of observed proportions vs. proportions expected from a uniform distribution. The proportions of dead (dry) pupae, live pupae (in prolonged dormancy), disintegrated pupae and total overwintering mortality were also compared among treatments using a $\chi^{2}$ test of observed proportions vs. proportions expected 


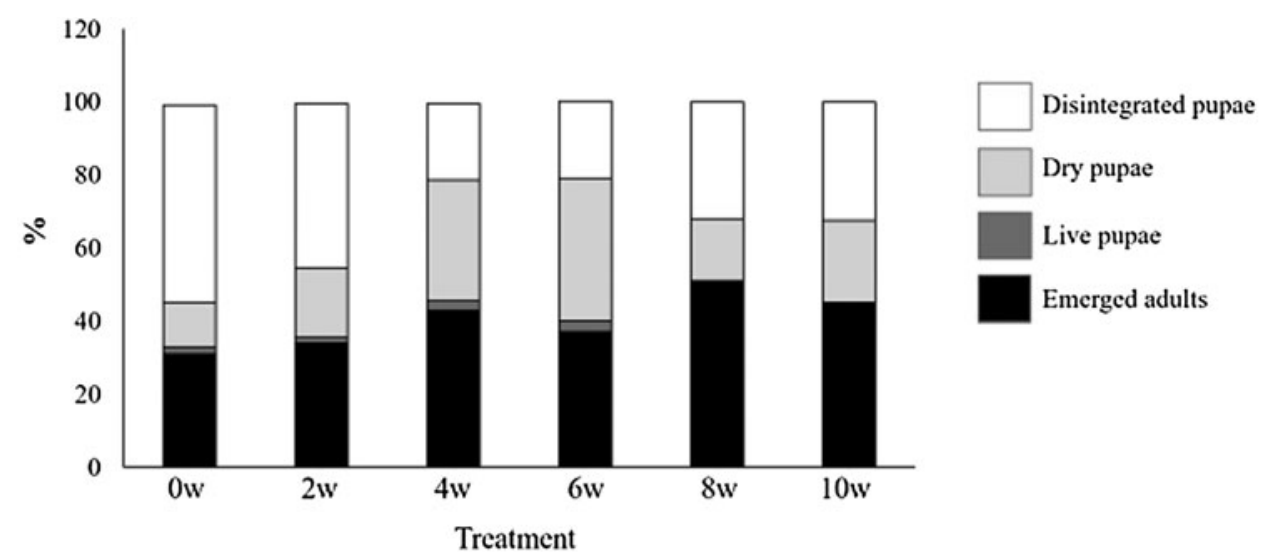

Figure 2. Per cent emerged adults, live (in prolonged dormancy) and dry (dead) pupae a year after collection, and disintegrated pupae.

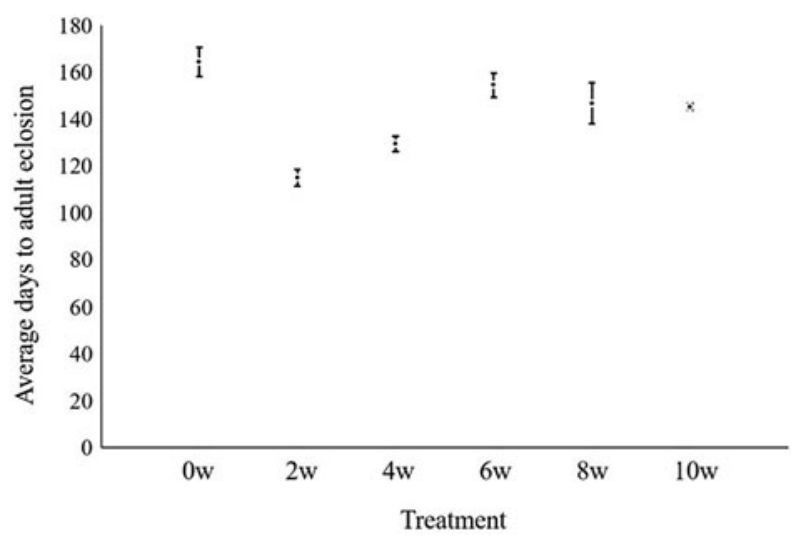

Figure 3. Average number of days from pupation to adult eclosion corrected for artificial winter length (by subtracting the time spent in the refrigerator under $8^{\circ} \mathrm{C}$ ) for Rhagoletotrypeta pastranai pupae subjected to artificial winters of different duration $(0,2,4,6,8$, and 10 weeks).

from a uniform distribution. The duration of dormancy (from pupation to adult emergence) in days corrected for winter length (artificial winter period subtracted) was compared among treatments with a GLM with duration as the dependent variable and sex and treatment as factors and replicate as a random factor. The age at sexual maturity was established with ANCOVA where size (head width) as a covariate and diet (sugar/sugar + protein) and ovary length, or ovary width, or number of mature eggs in the ovaries as dependent variables for females and testes width or length for males. Adult longevity was compared between sexes with a GLM with longevity in days as the dependent variable, sex as a categorical factor and replicate as a random factor.

\section{Results}

\section{Infestation levels}

A total of 1376 larvae were recovered from 807 Celtis tala drupes. Up to five larvae were recovered from individual fruit with an average $( \pm$ s.d.) of $0.85 \pm 0.84$ larvae per fruit. Larval recovery began 6 days after fruit collection and the longest time recorded was of 20 days. There was no significant relationship between fruit size and number of larvae per fruit $\left(R^{2}=0.08, P=0.08\right)$. A total of 426 adult flies (263 females and 163 males) and nine parasitoids emerged from recovered larvae over a year. Only four flies emerged without becoming dormant ( $<40$ days after pupation), whereas all but one parasitoid emerged within 40 days after pupation. Parasitoids were identified as an undescribed species of Utetes close to $U$. anastrephae (Viereck). Non-dormant parasitoids emerged $19.75 \pm 2.37$ days after pupation, while one individual female emerged 172 days after pupation. In the case of Celtis iguanea, only 11 pupae were recovered from 945 drupes out of which a single adult emerged 208 days after fruit collection.

\section{Effect of winter length of survival and duration of dormancy}

Of 326 adults recorded during observations on winter length, very few $(N=3)$ emerged from pupae without becoming dormant $(<40$ days). Winter length had no effect on survival (per cent adult emergence) of $R$. pastranai pupae exposed to $8^{\circ} \mathrm{C}$ for different time periods $\left(\chi^{2}=7.02, \mathrm{df}=5, P=0.21\right)$. A small proportion of flies entered in prolonged (>year) dormancy $(1.56 \pm 2.14 \%)$ but there were no differences in the proportions according to treatment $\left(\chi^{2}=7.02, \mathrm{df}=5, P=0.21\right)$. Large proportions of uneclosed pupae were dead (dry) after a year $(23.7 \pm 10.2 \%)$ $\left(\chi^{2}=21.8, \mathrm{df}=5, P=0.005\right)$ with pupae exposed to 4 , and $6 \mathrm{w}$ winters having larger proportions of dead pupae than expected from a uniform distribution. Large proportions of pupae were not found after a year in overwintering cups $(34.25 \pm 13.15 \%)$ $\left(\chi^{2}=24.8, \mathrm{df}=5, P<0.001\right)$ with pupae exposed to 0 and $2 \mathrm{w}$ winters having larger proportions of unaccounted pupae than expected from a uniform distribution. Overall overwintering mortality was high $(58 \pm 6.48 \%)$ with no significant difference among treatments $\left(\chi^{2}=4.67, \mathrm{df}=5, P=0.45\right)$ (fig. 2). Duration of dormancy was not affected by winter length $\left(F_{5,325}=0.679\right.$, $P=0.65$ ) (fig. 3). Average duration of dormancy was $144.9 \pm 3.9$ days for females and $143.2 \pm 3.38$ days for males which was not statistically different $\left(F_{5,325}=0.43, P=0.63\right)$.

\section{Age at sexual maturity}

There was no significant effect of diet $\left(F_{1,18}=0.55, P=0.46\right)$, age $\left(F_{3,18}=0.139, P=0.93\right)$ or the diet $\times$ age interaction $\left(F_{3,18}=0.138\right.$, $P=0.93)$ on testes width. There was no significant effect of diet on testes length $\left(F_{1,18}=0.58, P=0.45\right)$. By contrast, there was a significant effect of age on testes length $\left(F_{3,18}=3.39, P=0.04\right)$ with older males having longer testes, while the interaction diet×age was not significant $\left(F_{3,18}=0.58 ; P=0.63\right)$ (fig. 4). In the case of females, there was a significant effect of diet 


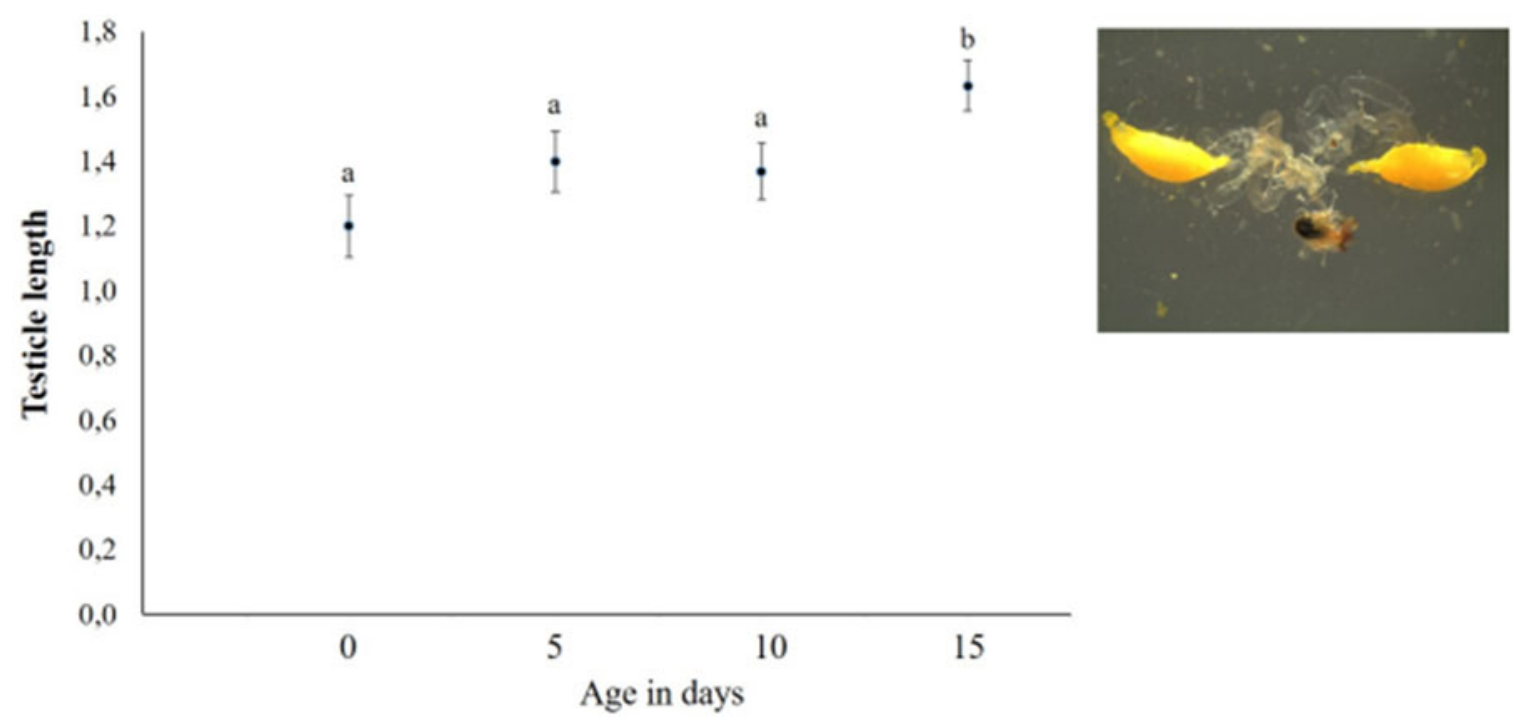

Figure 4. Average testes length according to age in days for five Rhagoletotrypeta pastranai males. Different letters above bars represent significant differences $(P<$ 0.05).
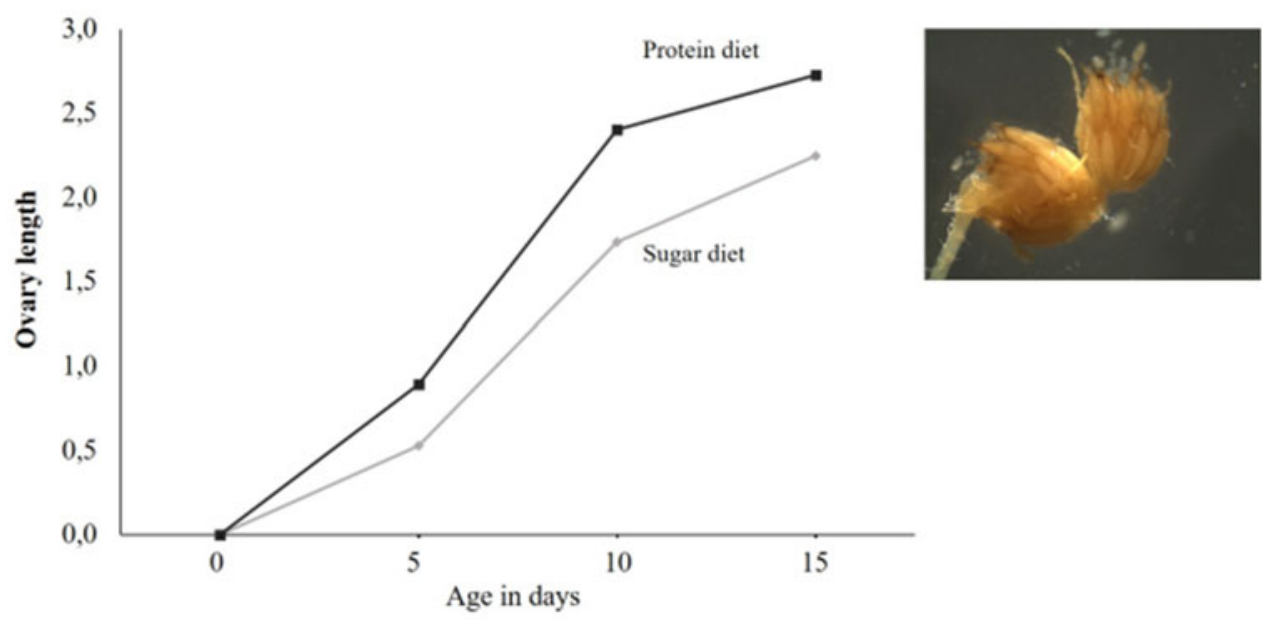

Figure 5. Average ovary length according to age in days for five Rhagoletotrypeta pastranai females fed a sugar (grey line) and a protein (black line) diet.

$\left(F_{1,18}=9.24, P=0.007\right)$ and age $\left(F_{3,18}=5.87, P=0.006\right)$ on ovary width while the interaction diet $\times$ age $\left(F_{3,18}=0.14, P=0.26\right)$ was not significant. Females fed a protein diet and older females had wider ovaries than sugar-fed flies and younger flies, respectively. Similarly, there was a significant effect of diet $\left(F_{1,18}=6.63\right.$, $P=0.019)$ and age $\left(F_{3,18}=4.49, P=0.016\right)$ on ovary length, while the interaction between diet $\times$ age $\left(F_{3,18}=1.11 ; P=0.37\right)$ was not significant (fig. 5). Finally, there was a significant effect of diet $\left(F_{1,18}=13.10, P<0.001\right)$, age $\left(F_{3,18}=21.96, P<0.001\right)$ and their interaction diet $\times$ age $\left(F_{3,18}=8.90, P=0.001\right)$ on the number of mature eggs in the ovaries. Older female flies fed a protein-rich diet had progressively more eggs in the ovaries while sugar-fed flies had few eggs irrespective of age (fig. 6).

\section{Behaviour and demography}

Sexual activity of $R$. pastranai in the laboratory was sparse with only four copulations recorded over $58 \mathrm{~h}$ of observation. All copulations occurred in the afternoon between 4 and $7 \mathrm{pm}$ and had an average duration of $80 \mathrm{~min}$. No apparent male courtship behaviour (e.g. pheromone emission, wing fanning or tactile approach) was observed. Males and females were occasionally observed visiting artificial fruit and when facing each other or an individual of their own sex, they exhibited a brief boxing event. Several copulation attempts were observed with males jumping on the female back but were most often resisted by females shaking and flying away and occasionally dropping to the cage floor. Copulations began on cage walls, ceiling or floor and in all cases, males that were seeking to mate, jumped and mounted on females apparently forcing them to copulate. Once intromission was achieved, females tended to hold their wings outward, positioning them in parallel to their bodies. Females exhibited host marking behaviour (dragging of the ovipositor) after egg laying. Eggs were laid singly in the artificial host with a small globular structure sticking out (fig. 7). Females fed a protein diet in the laboratory lived an average of $51.13 \pm 3.06$ days 

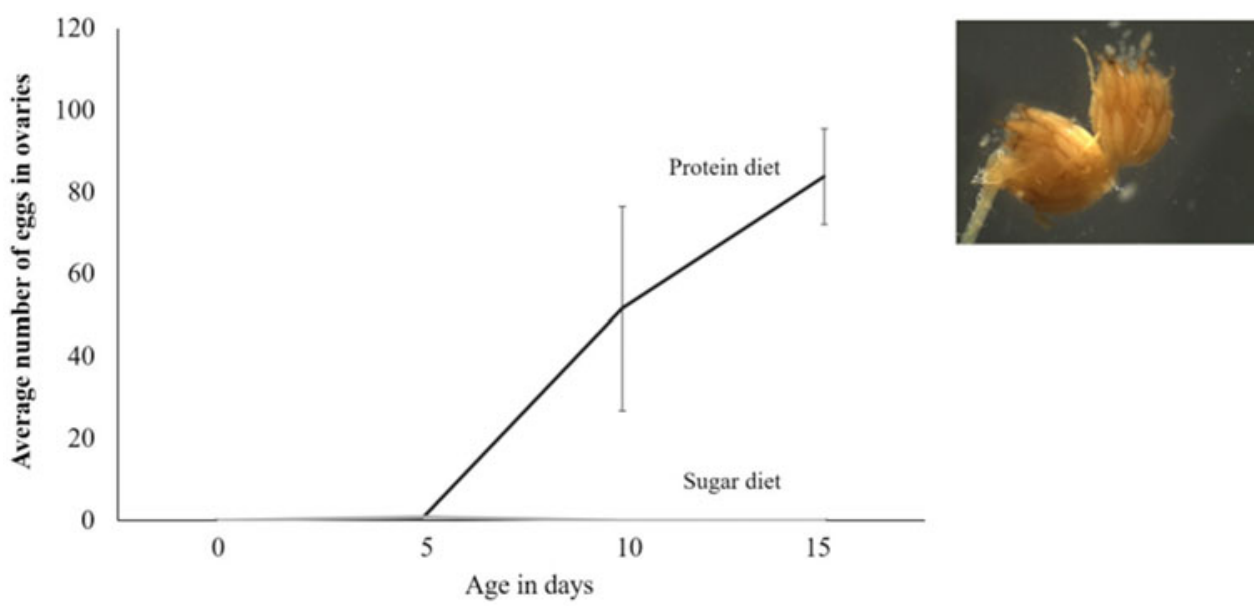

Figure 6. Average number of mature eggs in the ovaries according to age in days for five Rhagoletotrypeta pastranai females fed a sugar (grey line) and a protein (black line) diet.

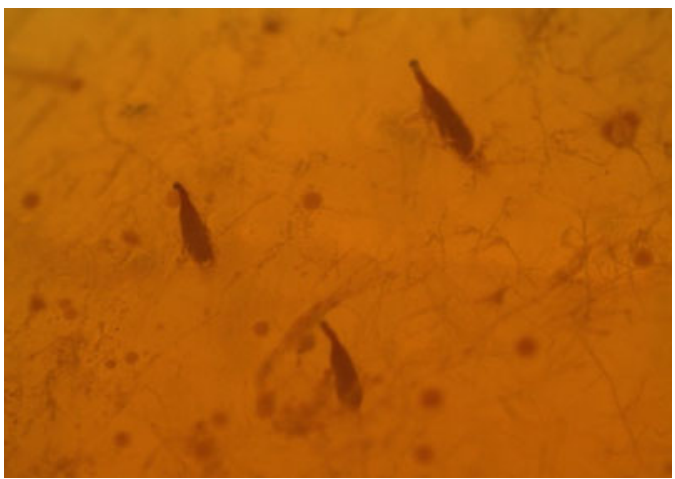

Figure 7. Eggs deposited in artificial agar egg laying spheres by Rhagoletotrypeta pastranai females.

while males lived an average of $48.08 \pm 3.76$ days and there was no significant difference in longevity between males and females $\left(F_{1,35}=0.78, P=0.43\right)$.

\section{Discussion}

Rhagoletotrypeta pastranai was found infesting fruits of Celtis tala and Celtis iguanaea trees in two sites located at 600-700 $\mathrm{m}$ a.s.l. in the Yungas ecoregion in Tucuman Province, consistent with records of the genus reported by Ovruski et al. (2005) in northwestern Argentina. On average, only one larva developed per fruit as is common in other species of Carpomyini (Averill and Prokopy, 1987; Ovruski et al., 2005; Rull et al., 2016, 2017) and there was no correlation between fruit size and number of larvae per fruit, perhaps owing to the fact that host fruits are small, abundant and very similar to each other with an average weight of $1.68 \pm 0.30 \mathrm{~g}$. A total of 426 adult flies emerged from 1376 recovered larvae from $C$. tala fruits over a year, of which only four individuals appeared without becoming dormant and the largest proportion of the population emerged after 40 days following pupation. Parasitism level was low with nine wasps emerged over a year of which only one became dormant and emerged 172 days after pupation. All parasitoids were identified as a species of Utetes genus close to $U$. anastrephae. Likewise, Leonel et al.
(1995, 1996), Ovruski et al. (2005) and more recently Palacio et al. (2019) reported that this species and other braconids such as Doryctobracon areolatus (Szepligeti), D. brasiliensis (Szepligeti) and Opius bellus (Gahan) were found associated with $R$. pastranai in Brazil and Argentina. For C. iguanaea, only 11 pupae were recovered from 945 collected drupes and only a single adult emerged after 208 days. There was no parasitoid emergence in this association.

Based on results of this work, $R$. pastranai can be considered a univoltine monophagous species with host specialization and a life cycle adapted to Celtis tala fruiting phenology; therefore, a large number of individuals undergo pupal dormancy and synchronize their reproductive stage with the main fruiting period of the host. According to Koštál (2006), dormancy is considered as a state of suppressed development that evolved among animals to cope with long periods of adverse conditions. In the case of $R$. pastranai, low temperatures in the winter in subtropical Tucumán rarely reach levels low enough to cause pupal mortality. Host scarcity is more likely to be the driving factor in the evolution of dormancy, and seasonal humidity and day-length (photoperiod) remain to be tested as factors of importance in the regulation and fine tuning of dormancy for this species. Although flies in the genera Anastrepha and Bactrocera are generally multivoltine, dormancy has also been reported in the subtropical species Anastrepha tehuacana (Norrbom et al., 2014) and Bactrocera minax (Dong et al., 2013). As R. pastranai, both of these subtropical flies are highly specialized and may not only face seasonal periods of environmental hardship but also long periods of host fruit scarcity, both of which may have influenced the evolution of dormancy.

Results on the effect of winter length on development and/or dormancy in the pupal stage of $R$. pastranai revealed that winter length has no effect on survival of pupae, of which only a small proportion entered prolonged dormancy, with a large quantity of dead uneclosed pupae after a year. Likewise, there was a considerable number of missing pupae in overwintering cups, possibly owing to the action of some microorganisms that had grown in the vermiculite substrate. Factors of diapause/dormancy regulation and their overwintering mechanisms are poorly understood in subtropical species (Danks, 2007), especially in members of the Carpomyini (Rull et al., 2017). Some factors, e.g. day length, 
pre-winter temperatures and winter duration, are less variable in tropical and subtropical regions than at higher latitudes (Denlinger, 1986; Feder et al., 2010); therefore, other environmental cues, such as rainfall and humidity fluctuations, might have more effect on diapause/dormancy duration, as reported by Araujo-Diniz et al. (2017) for tropical mosquitoes species.

As mentioned above, the majority of individuals became dormant and emerged after about 145 days after pupation under laboratory conditions. Nevertheless, Ovruski et al. (2005) and Palacio et al. (2019) reported that the pupal stage could last up to 12 months under uncontrolled conditions. Furthermore, dissections of males and females revealed that a short period of sexual maturation is necessary for both sexes and that they require feeding on protein sources to reach full development of sexual organs; $R$. pastranai is therefore, as most species of frugivorous Tephritidae (Drew and Yuval, 1999), an anautogenous species. Adult male and female longevity was similar, with an average duration of 51 and 48 days, respectively. This constitutes the first report of lifetime duration of the adult stage for a species of Rhagoletotrypeta.

Behavioural observations were carried out on sexually mature males and females under laboratory conditions. Sexual activity was scarce with only four copulations occurring during the entire observational period, all in the afternoon. This temporal pattern might have evolved in response to natural conditions during the fruiting season of $C$. tala where temperatures at that time of the day might be similar to those we applied in the laboratory. According to our observations, the mating system can be classified as resource defence by males, which is common among the Carpomyini group (Prokopy and Papaj, 1999; Rull et al., 2017). However, because of the low number of copulations observed under laboratory conditions, and considering the fact that most species of Carpomyini whose sexual behaviour has been observed are highly promiscuous (Prokopy and Papaj, 1999; Opp and Prokopy, 2000; Rull et al., 2017), we believe that behavioural observations in the field are necessary to conclusively characterize the mating system of this species. Host derived stimuli have been found to influence ovarian development and sexual behaviour of Rhagoletis juglandis (Lachman and Papaj, 2001) another species of Carpomyini. Plant volatiles also enhance mating behaviour of the Mediterranean fruit fly Ceratitis capitata (Shelly et al., 2004), and play an important role in the sexual behaviour of several species of Bactrocera (Shelly, 2010). In the case of R. pastranai, the presence of suitable host fruit, and the volatiles they release might be stimuli triggering sexual behaviour or female receptivity. The lack of host-derived stimuli during our observations could therefore explain the low numbers of observed copulations.

Females laid a single egg per egg-laying bout and dragged their ovipositor to mark artificial host fruit. Such behaviour has also been observed for several species in the genera Anastrepha, Ceratitis and Rhagoletis but does not occur among Bactrocera species (Díaz-Fleischer et al., 1999). In the case of $R$. pomonella where females mark fruits with a contact pheromone to dissuade other females from laying eggs in a fruit in which a larva is already developing. Consequently, this chemical communication might reduce intraspecific competition among larvae that exploit an ephemeral host (Averill and Prokopy, 1987). In general, with the exception of walnut-infesting species, for flies in the genus Rhagoletis, a single larva develops per fruit and the oldest larva apparently kills later arrivals (Averill and Prokopy, 1987). In the case of Rhagoletotrypeta, we found that up to five larvae could develop to pupae in a single fruit. It would be interesting to examine if multiple larvae in a single fruit are siblings or if the progeny of different females can coexist.

Our work constitutes the first study on the natural history of $R$. pastranai. It describes interesting aspects of life history and mating behaviour of this species and contributes to the knowledge of the biology of non-economically important groups within the Tephritidae, particularly in the Carpomyini. It also highlights the value of investigating such species, considering that only $5 \%$ of the nearly 5000 described tephritids are considered pestiferous (Aluja, 1999; Norrbom, 2004). Nevertheless, further research including observations of diel activity patterns in the field emphasizing sexual behaviour before, during and after mating, and experimental studies that explore the effects of different environmental factors on dormancy/diapause regulation, are necessary to broaden our comprehension and understanding of the evolution of overwintering mechanisms in subtropical insects and the evolution of mating systems and life history strategies.

Acknowledgement. A. Moyano thanks Consejo Nacional de Investigaciones Científicas y Técnicas (CONICET, Argentina) for a granted scholarship. This study was supported by the Fund for Scientific and Technological Research (grants PICT 2013-0604, PICT 2015-2631 and PICT 2015-0191, Argentina).

\section{References}

Aluja M (1999) Fruit fly (Diptera: Tephritidae) research in Latin America: myths, realities and dreams. Anais da Sociedade Entomológica do Brasil (currently Neotropical Entomology) 28, 565-594.

Araujo-Diniz DF, Ribeiro de Albuquerque CM, Oliveira Oliva L, Varjal de Melo-Santos MA and Junqueira Ayres CF (2017) Diapause and quiescence: dormancy mechanisms that contribute to the geographical expansion of mosquitoes and their evolutionary success. Parasites \& Vectors 10, 310.

Averill AL and Prokopy RJ (1987) Intraspecific competition in the tephritid fruit fly Rhagoletis pomonella. Ecology 68, 878-886.

Berg CC and Dahlberg SV (2001) A revision of Celtis Subg. Mertensia (Ulmaceae). Brittonia 53, 66-81.

Boucher J, Ashley R and Adams R, Jr (2005) Quantifying pepper maggot (Diptera: Tephritidae) oviposition and infestation over time. Journal of Economic Entomology 98, 350-357.

Brown A, Grau H, Malizia L and Grau A (2001) Bosques Nublados del Neotrópico en Argentina. In Kappelle $\mathrm{M}$ and Brown $\mathrm{AD}$ (eds), Bosques Nublados del Neotrópico. Costa Rica: Editorial INBio, pp. 623-659.

Brown A, Pacheco S, Lomáscolo T and Malizia L (2006) Ecoregión yungas. In Brown A, Martínez Ortiz U, Acerbi M and Corcuera J (eds), La Situación Ambiental Argentina 2005. Buenos Aires, Argentina: Fundación Vida Silvestre, pp. 53-61.

Costello MJ, Wilson S and Houlding B (2012) Predicting total global species richness using rates of species description and estimates of taxonomic effort. Systematic Biology 61, 871-883.

Climate-Date.org (2020) (Accessed 5 Feb 2020).

Danks HV (2007) The elements of seasonal adaptations in insects. The Canadian Entomologist 139, 1-44.

Denlinger DL (1986) Dormancy in tropical insects. Annual Review of Entomology 31, 239-264.

Díaz-Fleischer F, Papaj DR, Prokopy RJ and Norrbom AL (1999) Evolution of fruit fly oviposition behavior. In Aluja $\mathrm{M}$ and Norrbom AL (eds) Fruit Flies (Tephritidae): Phylogeny and Evolution of Behavior. Boca Raton, FL: CRC Press, pp. 811-841.

Dong YC, Wang ZJ, Clarke AR, Pereira R, Desneux N and Niu CY (2013) Pupal diapause development and termination is driven by low temperature chilling in Bactrocera minax. Journal of Pest Science 86, 429-436.

Dottori N and Hunziker AT (1994) Celtidaceae. In Hunziker AT (ed.) Flora Fanerogámica Argentina. Fascículo 2. Córdoba, Argentina: PROFLORA (CONICET), pp. 5-11. 
Drew RAI and Yuval B (1999) The evolution of fruit fly feeding behavior. In Aluja M and Norrbom AL (eds) Fruit Flies (Tephritidae): Phylogeny and Evolution of Behavior. Boca Raton, FL: CRC Press, pp. 731-749.

Feder JL, Powell TH, Filchak KE and Leung B (2010) The diapause response of Rhagoletis pomonella to varying environmental conditions and its significance for geographic and host plant-related adaptation. Entomologia Experimentalis et Applicata 136, 31-44.

Hernández-Ortiz V, Guillén-Aguilar J and López L (2011) Taxonomía e identificación de moscas de la fruta de importancia económica en América. In Montoya P, Toledo J and Hernández E (eds), Moscas de la Fruta: Fundamentos $y$ Procedimientos para su Manejo. México D.F., México: S y G Eds, pp. 49-80.

Jaldo HE, Gramajo MC and Willink E (2001) Mass rearing of Anastrepha fraterculus (Diptera: Tephritidae): a preliminary strategy. Florida Entomologist 84, 716-718.

Koštál V (2006) Eco-physiological phases of insect diapause. Journal of Insect Physiology 52, 113-127.

Lachmann AD and Papaj DR (2001) Effect of host stimuli on ovariole development in the walnut fly, Rhagoletis juglandis (Diptera. Tephritidae). Physiological Entomology 26, 38-48.

Leonel FL, Jr, Zucchi RA and Wharton RA (1995) Distribution and tephritid hosts (Diptera) of braconid parasitoids (Hymenoptera) in Brazil. International Journal of Pest Management 41, 208-213.

Leonel FL, Jr, Zucchi RA and Canal Daza NA (1996) Parasitismo de moscas-das-frutas (Diptera: Tephritidae) por Braconidae (Hymenoptera) en duas localidades do Estado de Sao Paulo. Anais da Sociedade Entomológica do Brasil 25, 199-205.

Mora C, Tittensor DP, Adl S, Simpson AGB and Worm B (2011) How many species are there on earth and in the ocean? PLoS Biology 9, e1001127.

Norrbom AL (1994) New species and phylogenetic analysis of Cryptodacus, Haywardina, and Rhagoletotrypeta (Diptera: Tephritidae). Insecta Mundi 8, 37-65.

Norrbom AL (2004) Updates to biosystematic database of world Diptera for Tephritidae through 1999. Diptera Data Dissem. Disk (CD-ROM) 2.

Norrbom AL, Carroll LE, Thompson FC, White IM and Freidberg A (1999) Systematic database of names. In Thompson FC (ed) Fruit Fly Expert Identification System and Systematic. Information Database. Leiden, Netherlands: Backhuys Publ., pp. 65-299.

Norrbom AL, Castillo-Meza AL, García-Chávez JH, Aluja M and Rull J (2014) A new species of Anastrepha (Diptera: Tephritidae) from Euphorbia tehuacana (Euphorbiaceae) in Mexico. Zootaxa 3780, 567-576.

Norrbom AL, Savaris MA and Marinoni L (2016) New species of Rhagoletotrypeta (Diptera: Tephritidae) from the Dominican Republic and southern Brazil and Paraguay. Zootaxa 4088, 547-554.

Nufio CR, Papaj DR and Alonso-Pimentel H (2000) Host utilization by the walnut fly, Rhagoletis juglandis (Diptera: Tephritidae). Environmental Entomology 29, 994-1001.

Opp SB and Prokopy RJ (2000) Multiple mating and reproductive success of male and female apple maggot flies Rhagoletis pomonella (Diptera: Tephritidae). Journal of Insect Behavior 13, 901-914.

Ovruski SM, Norrbom AL, Schliserman P and Aluja M (2005) Biology and taxonomy of Rhagoletotrypeta (Diptera: Tephritidae): a new species from
Cuba and new host plant, parasitoid and distribution records from northwestern Argentina. Annals of the Entomological Society of America 98, 252-258.

Palacio FX, Lacoretz MV, Perez EC and Ordano M (2019) On a poorly known tritrophic interaction: fruit-infesting Rhagoletotrypeta pastranai Aczél (Diptera: Tephritidae) and its parasitoid Utetes Anastrephae (Viereck) (Hymenoptera: Braconidae) in Celtis ehrenbergiana (Klotzsch) Liebm. (Rosales: Cannabaceae) fruits. Revista de la Sociedad Entomológica Argentina 78, 29-32.

Prokopy RJ and Papaj DR (1999) Behavior of flies of the genera Rhagoletis, Zonosemata, and Carpomya (Trypetinae: Carpomyina). In Aluja M and Norrbom AL (eds) Fruit Flies (Tephritidae): Phylogeny and Evolution of Behavior. Boca Raton, FL: CRC Press, pp. 219-252.

Romanczuk MC and Del Pero de Martínez M (1978) Las especies del género Celtis (Ulmaceae) en la flora Argentina. Darwiniana 21, 542-577.

Rull J, Abraham S, Tadeo E and Rodriguez CL (2016) Life history and mating behavior of Rhagoletis solanophaga (Diptera: Tephritidae), nondiapausing species with highly variable mating duration. Journal of Insect Behaviour 29, 629-642.

Rull J, Abraham S, Schlisermann P, Ordano M and Ovruski S (2017) Mating behavior and basic biology of Haywardina cuculi (Diptera: Tephritidae), a poorly known species exhibiting high variability in copulation duration. Journal of Insect Behavior 30, 439-453.

Rull J (2020) Distribución y relevancia del género Rhagoletis en México. In Montoya P, Toledo J and Hernández E (eds.) Moscas de la Fruta: Fundamentos y procedimientos para su manejo. Ciudad de México: S y G editores, pp. 165-184.

Shelly T (2010) Effects of methyl eugenol and raspberry ketone/cue lure on the sexual behavior of Bactrocera species (Diptera: Tephritidae). Applied Entomology and Zoology 45(3), 349-361.

Shelly TE, McInnis DO, Pahio E and Edu J (2004) Aromatherapy in the Mediterranean fruit fly (Diptera: Tephritidae): sterile males exposed to ginger root oil in prerelease storage boxes display increased mating competitiveness in field-cage trials. Journal of Economic Entomology 97, 846-853.

Smith JJ and Bush GL (1999) Phylogeny of the subtribe Carpomyina (Trypetinae), emphasizing relationships of the genus Rhagoletis. In Aluja $\mathrm{M}$ and Norrbom AL (eds.). Fruit Flies (Tephritidae): Phylogeny and Evolution of Behavior. Boca Raton, FL: CRC Press, pp. 187-217.

Stork N (2018) How many species of insects and other terrestrial arthropods are there on Earth? Annual Review of Entomology 63, 31-45.

Wiegmann BM, Trautwein MD, Winkler IS, Barr NB, Kim JW, Lambkin C, Bertone MA, Cassel BK, Bayless KM, Heimberg AM, Wheeler BM, Peterson KJ, Pape T, Sinclair BJ, Skevington JH, Blagoderov V, Caravas J, Kutty SN, Schmidt-Ottm U, Kampmeier GE, Thompson FC, Grimaldi DA, Beckenbach AT, Courtney GW, Friedrich M, Meier $\mathbf{R}$ and Yeates DK (2011) Episodic radiations in the fly tree of life. Proceedings of the National Academy of Sciences 108, 5690-5695.

Yee WL, Hernández-Ortiz V, Rull J, Sinclair BJ and Neven LG (2014) Status of Rhagoletis (Diptera: Tephritidae) pests in the NAPPO countries. Journal of Economic Entomology 107, 11-28. 